\title{
Effect of Agricultural Land Use on the Water Quality of Polish Lakes: a Regional Approach
}

\author{
Wojciech Sobolewski* \\ Department of Hydrology, Faculty of Earth Sciences and Spatial Management Maria Curie-Skłodowska University \\ Kraśnicka 2cd, 20-718 Lublin, Poland
}

Received: 15 April 2016

Accepted: 11 June 2016

\begin{abstract}
There is a need to collect and store fast-growing resources of information describing phenomena and processes occurring in the nature, and therefore, databases are increasingly being used in environmental sciences. The possibility of formulating arbitrarily complicated queries enables in the precise determination of the scope and method of analysis using a large amount of historical and actual datasets. This study used a database containing the morphometric parameters of more than 1,000 lakes and their catchments, and basic data describing the quality of water of more than 560 lakes. In the first step of the analysis, the percentage share of agricultural land in the total area of each region was determined. The next stage was to divide the entire set of lakes into equinumerous class breaks based on the values of water quality parameters. Then, the lakes located in individual regions were counted within the groups of low, medium, and high values of studied parameters. Numbers of lakes have been converted to percentages and used to calculate the values of the regional water quality indicator. It was concluded that the values of the indicator are dependent on the type of land use, and in particular, on the percentage of agricultural land that exists within the studied regions.
\end{abstract}

Keywords: lakes, land use, surface water quality, lakeland, database of Polish lakes

\section{Introduction}

During the second half of the 20th century, agricultural productivity increased due to the increased use of irrigation, fertilization, and pesticides [1]. The agricultural sector is the greatest water user in the world [2-3], making this branch of the economy a significant cause of environmental hazards. The main agricultural pollutants are nutrients and pesticides [4-5]. Nutrients

*e-mail: potamologia@tlen.pl limit life in aquatic ecosystems, and their accumulation promotes excessive plant growth. High loads of nitrogen and phosphorus cause eutrophication, hypoxia, and algal blooms in surface water bodies [6]. This is the main reason for the drastic reduction in water quality in the world today. The upper tolerable limit for freshwater eutrophication has already been crossed [7].

The role of catchments in impacting the quality of lake water is important [8-9]. Excess inputs of nutrients to lakes can cause eutrophication and the associated decline of water quality and ecological integrity [10]. The 
poor condition of a lake is a consequence of progressive eutrophication [11]. Effects of this process have been extensively described in the limnological literature [1213]. Many types of pollutants enter surface waters from urban, industrial, and agricultural land. Due to the use of large areas of arable land, agricultural activity is a major provider of nutrients and harmful chemicals [14]. This leads to the rapid deterioration of lake water quality. The amount of pollution from anthropogenic sources is increasing in some parts of the world and greatly exceeds the natural nitrogen and phosphorus loads in the surface water [15]. Researchers have traditionally focused on the study of in-lake processes [16], but the successful prevention of nutrient pollution is dependent on the nature of the links connecting the lakes and their catchments [17]. Many scientific papers have been written in recent years that indicate an interest in catchment impact on water quality of rivers and lakes. Studies have been conducted on a variety of objects, such as mountain rivers [18], lowland agricultural catchments [19], upland catchments [20], lakes located in national parks and landscape parks of Poland, and many others [21]. However, the problem of agricultural pollution of water should also be seen in a regional context, because "regional" denotes the spatial extent of such factors as soil and climatic conditions, the level of economic development, or agricultural traditions affecting the methods of land cultivation.

The objective of this study was to establish the relationship between the quality of lake waters and agricultural land use in the area of Polish lake districts. The study used the data collected and published by the Polish environmental monitoring services. The analysis was limited to five parameters: Secchi depth, electrolytic conductivity, concentrations of total nitrogen, concentrations of total phosphorus, and content of chlorophyll "A" in water samples. The aim of the investigation has been achieved by demonstrating the existence of significant regional diversity of lake water quality and by collating the calculated values of the water quality indicator with percentages of agricultural land in the regions covered by the study. Analysis of the results helped in identifying the most vulnerable areas and in proposing necessary improvements to environmental management strategy in order to obtain acceptable water quality in Polish lakes.

\section{Material and Methods}

Poland is considered to be a lowland country for the most part because more than $70 \%$ of its territory lies below an altitude of $200 \mathrm{~m}$ a.s.l. The northern and central parts of Poland can be divided into the following zones: coastal lowlands, lakelands, and central lowlands [22]. This terrain forms part of the North European Plain and the East European Plain. The Lakeland areas form a wide strip of land stretching from the western to the eastern border of Poland. A detailed geographic division of the study area is shown in Fig. 1.

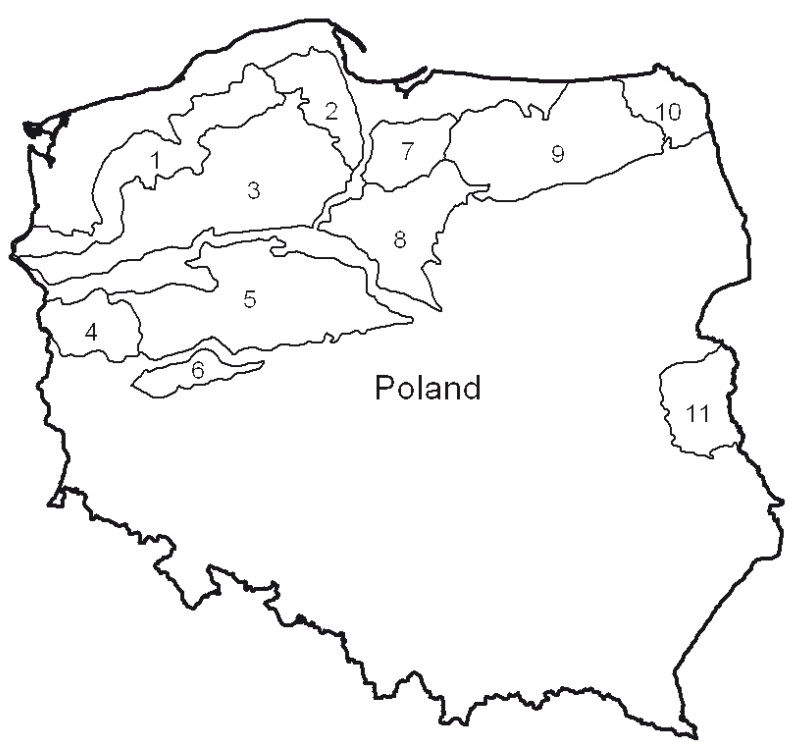

Fig. 1. The regions included in the study: 1-West Pomeranian Lakeland, 2-East Pomeranian Lakeland, 3-South Pomeranian Lakeland, 4-Lubuskie Lakeland, 5-Wielkopolskie Lakeland, 6-Leszno Lakeland, 7-Ilawa Lakeland, 8-Chelmno-Dobrzyn Lakeland, 9-Masurian Lakeland, 10-Lithuanian Lakeland, and 11-Western Polesie.

The northern part of Poland is characterized by a specific landscape of glacial relief formed during the Pleistocene. A series of glacial events separated by interglacials occurred during the period from about 2.6 million years ago to the present [23]. The major effects of the ice age are erosion and deposition of material over large parts of Northern Poland, modification of river systems, and the creation of thousands of lakes. The ice sheet left behind physical evidence of its presence in the forms of moraine hills, valleys, local depressions, and fields of glacial mineral deposits. Pleistocene glaciations in Poland were a dominant factor in the creation of the landscapes that exist today. Western Polesie, a region located in east-central Poland, is an area of landscape shaped during older glaciations. The terrain surface is flat and covered with sedimentary rocks of the Pleistocene and Holocene [24]. The lakes of Western Polesie are part of a larger lake district located on the border area of Poland, Ukraine, and Belarus.

There are more than 7,000 lakes in Poland with an area larger than 1 hectare, and their total area is $2,813.77 \mathrm{~km}^{2}$ [25]. The presence of such a significant number of water bodies makes the northern part of Poland relatively wealthy in water resources. It should be noted, however, that the waters of these lakes are diverse in terms of quality. The research terrain presents both clean lakes that contain water of the highest quality, and heavily contaminated lakes that demonstrate an extremely poor ecological status.

A database of Polish lakes was created to describe the physical and chemical properties of lake waters. The dataset contains information on the climatic, hydrological, 
and hypsometric conditions of lakelands, the land use characteristics of catchments, and the quality of lake waters. To create an information system, the digital data available from a variety of sources were used, including meteorological and hydrological data made available by the Institute of Meteorology and Water Management in Warsaw, CORINE Land Cover data derived from the European Environment Agency, topographic digital maps provided by the Documentation Center of Geodesy and Cartography in Warsaw, and information about the lakes published during the period 1981-2012 by the State Inspectorate for Environmental Protection.

Geographic (spatial) data forming the geographic information system (GIS) and descriptive data were used to create the integrated database of Polish lakes. The main selection criterion for lakes included in the database was an area of at least 50 hectares. At the current stage of project development, the information system contains a set of morphometric parameters for more than 1,000 lakes and a basic dataset on water quality of more than 500 lakes. This database can be subjected to all kinds of transformations and analyses using the tools provided by the GIS software and database management system (DBMS). The study involved five parameters, which are used as basic indicators to characterize the quality of lake water: transparency (Secchi depth), electrolytic conductivity, concentration of total nitrogen, concentration of total phosphorus, and content of chlorophyll " $\mathrm{A}$ " in the water. The entire set of studied lakes was divided into equinumerous class breaks, according to the values of individual parameters. The classes were defined as groups of objects of small, medium, or large parameter values. Boundary values used in this classification are shown in Table 1. Lakes belonging to the classes designated in this way were counted for individual regions and presented as percentages of the studied statistical populations.

On the basis of the CORINE land cover digital dataset, the percentage share of the two most important forms of land use (agricultural land and forests) in the total area of the regions characterized by the presence of a large number of lakes was fixed. A simple rating system that took into account all the parameters analyzed was used to describe in a synthetic manner the quality of lake water in the regions surveyed. The method worked by allocating evaluation points to individual regions. The

Table 1 . Classes of water quality parameters.

\begin{tabular}{|c|c|c|c|}
\hline \multirow{2}{*}{ Parameter } & \multicolumn{3}{|c|}{ Parameter value } \\
\cline { 2 - 4 } & low & medium & high \\
\hline Secchi depth $(\mathrm{m})$ & $<1.15$ & $1.15-2.10$ & $>2.10$ \\
\hline $\begin{array}{c}\text { Electrolytic conductivity } \\
(\mu \mathrm{S} \mathrm{cm}\end{array}$ & $<289$ & $289-402$ & $>402$ \\
\hline Total nitrogen $\left(\mathrm{mg} \cdot \mathrm{dm}^{-3}\right)$ & $<1.04$ & $1.04-1.67$ & $>1.67$ \\
\hline Total phosphorus $\left(\mathrm{mg} \cdot \mathrm{dm}^{-3}\right)$ & $<0.043$ & $0.043-0.08$ & $>0.08$ \\
\hline Chlorophyll "A" $\left(\mu \mathrm{g} \cdot \mathrm{dm}^{-3}\right)$ & $<12.5$ & $12.5-31.5$ & $>31.5$ \\
\hline
\end{tabular}

number of points (from 0 to 2 ) depended on which group of parameter values (high, medium, low) most closely described the lakes of the evaluated region. When the basis for the evaluation was Secchi depth, the highest number of points was assigned to those regions where the majority of the lakes were characterized by a high value for this parameter. In other cases, the best assessment was obtained by those regions where the majority of the lakes had low values for the analyzed parameters. The sum of the points allocated to each region is treated as a regional indicator of water quality.

\section{Results and Discussion}

The most forested regions are Lubuskie Lakeland and South Pomeranian Lakeland, where forests cover more than half of the area of these regions. The area of land used in these regions for agriculture does not exceed $40 \%$ of total area. A significant area of forests (over 35\% to almost $40 \%$ of the region) also characterized the West Pomeranian Lakeland, Lithuanian Lakeland, and Masurian Lakeland. Agricultural use accounts for about half of the total area of these three regions. A characteristic feature of these lands is the presence of lakes of a large area and significant water capacity. The share of surface waters in the total region area is more than $6.4 \%$ in the Masurian Lakeland and approximately $4 \%$ in the Lithuanian Lakeland.

The East Pomeranian Lakeland, Leszno Lakeland, and Ilawa Lakeland are regions of strongly marked agricultural character. Cultivated fields account for more than $60 \%$, and forests cover about $25 \%$ to $30 \%$ of the total area of these regions. However, regions that are predominantly agricultural are the Chelmno-Dobrzyn Lakeland and Wielkopolskie Lakeland, where agricultural use accounts for more than $70 \%$ of the total area. Forests cover only about $20 \%$ of these regions. Western Polesie is an area of extensive agriculture and forestry, with a large percentage share of meadows, pastures, and peat bogs, which occupy about $20 \%$ of the surface area. In the southern part of this region, there is a group of old, gradually disappearing lakes characterized by fairly good water quality.

Several studies carried out throughout the world have shown that nutrient pollution from agriculture has contributed to the eutrophication of many aquatic ecosystems on local and regional scales [26]. It is widely believed that forests moderate climatic extremes and have an effect on important characteristics of surface water, such as the quantity, quality, and thermal regime [27]. In regions that are more forested (Lubuskie Lakeland, South Pomeranian Lakeland) and that have a smaller percentage of land used by agriculture, most of the researched lakes were characterized by high water transparency, low electrolytic conductivity, and low values for the concentrations of nitrogen, phosphorus, and chlorophyll "A." Forested catchments are known worldwide for producing high-quality water [28]. According to Davis [29], nitrogen response in the afforested catchment varied over time, but long-term research has shown a decline 
in the concentration of contamination within five years of planting. It is also known [30] that in two or three years after forest harvesting, nitrate concentrations in the stream water of the deforested site exceed the health level recommended for drinking water.

When the information of classified lakes was compared with the data describing the land use in the studied regions, it was easy to notice that there is a relationship between agricultural land use and the quality of lake water in the studied areas. Agriculture is recognized as one of the branches of the economy that has led to major problems in water environments such as eutrophication and ecosystem damage. In European Union countries, various measures have been introduced as part of catchment basin management planning as a means of tackling problems of diffuse pollution from agriculture [31]. In agricultural areas of Poland, a large number of lakes were characterized by high electrolytic conductivity and small Secchi depth as well as high concentrations of nitrogen, phosphorus, and chlorophyll. The results of a study carried out on a regional scale are consistent with the conclusions obtained on the basis of detailed research on individual lakes or river systems [32-33].

The parameters that significantly modify the quality of lake water are the ability to form thermal stratification (related to the depth of the lake) and the value of coefficient calculated as the ratio of drainage basin area to lake volume [34], known as Schindler's ratio. This indicator shows the strength of the impact of catchment on lake water quality. The influence of morphometric parameters of lakes on water quality has been described by many researchers [3536]. The effect of lake basin and catchment characteristics on the number of lakes described by low, medium, and high values of parameters of water quality has been seen across the Masurian and Wielkopolskie lakelands.

In the region of the Masurian Lakeland, nearly $60 \%$ of the lakes described by a low Schindler's ratio were characterized by highly transparent water, and more than $52 \%$ of such lakes were distinguished by low concentrations of chlorophyll "A." Almost half of the stratified lakes contain water of high transparency and are characterized by a low content of chlorophyll. Among the shallow lakes, where there is no phenomenon of stratification, it was noticeable that $60 \%$ of them were of high concentrations of chlorophyll. Almost $87 \%$ of such shallow lakes were characterized by low or medium values for Secchi depth.

In the region of the Wielkopolskie Lakeland, many lakes exhibit poor water quality parameters. In particular, shallow lakes, where there is no stratification phenomenon, were characterized by a low transparency of water (nearly $80 \%$ of lakes), a high content of chlorophyll (nearly $76 \%$ of lakes), and a high electrolytic conductivity value (over $81 \%$ of lakes). It is also possible in this area to identify many examples of the strong influence of the catchment basin on water pollution in many lakes. Among the lakes described by a high Schindler's ratio, the majority were characterized by low water transparency (almost $60 \%$ of the surveyed locations), high water electrolytic conductivity (almost 89\%), and a high content

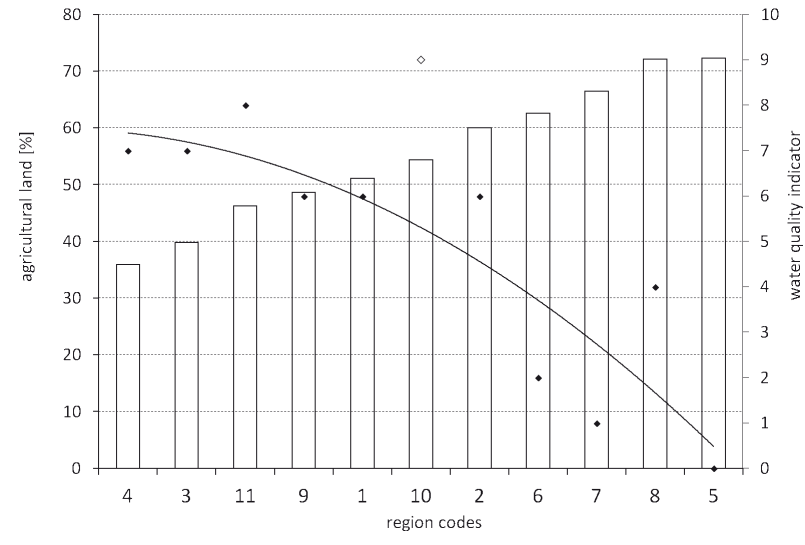

Fig. 2. The relationship between the percentage of agricultural land (bars) and the value of the water quality indicator (points). Region codes are the same as in Fig. 1.

of chlorophyll (almost 65\%). Lakes described by a low Schindler's ratio are less susceptible to the impact of the catchment area. A significant number of such lakes (more than $55 \%$ ) were distinguished by clear water and a small amount of chlorophyll.

The comparison of the percentage of land area used for agricultural purposes and the value of the regional indicator of water quality (wqi) has made it possible to determine the relationship between these variables. The final result is presented in the form of a graph (Fig. 2). Low values of $w q i$ were assigned to predominantly agricultural regions, namely Wielkopolskie Lakeland, Ilawa Lakeland, Leszno Lakeland, and Chelmno-Dobrzyn Lakeland. Highly ranked were regions with a small ratio of area used for agriculture (Lubuskie Lakeland, South Pomerania Lakeland). Spearman's rank correlation test was used to evaluate the relationship between the variables described. This method of data analysis is appropriate for continuous and discrete variables, including ordinal variables. It assesses how well the relationship can be described using a monotonic function [37]. Spearman's rank correlation coefficient $\left(r_{s}\right)$ is a nonparametric measure of statistical dependence between two variables. Rank correlation test showed that there is a strong inverse relationship between the ratio of agricultural land use and $w q i$ value. This is evidenced by the high correlation coefficient $r s=-0.786$ and the level of statistical significance $p=0.017$.

Lithuanian Lakeland (code 10) stands out clearly against other regions. This is a specific terrain with a significant percentage of the lakes area (about 4\%) in the total region area. Numerous deep, stratified lakes are located there. These conditions affect positively the purity of lake water in that region. Spearman's rank correlation test performed for the remaining 10 regions showed that the inverse monotonic relationship between examined variables is very strong $\left(r_{s}=-0.911\right.$ and $p$-level $\left.=0.004\right)$. This relationship can be approximated by the exponential function $w q i=-0.0034 p_{a}^{2}+0.197 p_{a}+4.7606$ (where $p_{a}$ is the percentage of a region's land area used for agriculture). 


\section{Conclusions}

This study performed a classification of regions, taking into account several characteristics of the quality of lake water. The results were compared with the percentages of agricultural land in the area of the regions surveyed. Spatial diversity of lake water quality in the study area is clearly visible. The majority of lakes located in agricultural regions were characterized by low water transparency and a high concentration of nitrogen and phosphorus, as well as a large amount of chlorophyll contained in the water. Examples of such regions include Wielkopolskie Lakeland, Ilawa Lakeland, and Leszno Lakeland. A contrasting situation is observed in areas where there are extensive forests and numerous large and deep lakes. Such conditions occur in the Lithuanian, Masurian, and West Pomeranian lakelands. Water of a large number of lakes located in these regions was characterized by high levels of water transparency, a low content of chlorophyll, low levels of total nitrogen and total phosphorus, and low electrolytic conductivity. The values of the parameters generally regarded as decisive in an assessment of lake water quality were strongly influenced by land use type, and in particular by the proportion of agricultural land within the entirety of a given region.

The majority of polluted lakes exist in agricultural regions. Detailed analysis of the database of Polish lakes indicates that in many cases the water quality of such lakes is very poor. Terrain observations and results obtained from the analysis of information collected in the database led to the conclusion that the most effective way to improve the purity of lakes in Poland is to introduce preventive measures in catchments of lakes located within agricultural regions. The new policy of water quality protection and improvement should be based on proper management of the catchment area, and above all on the introduction of appropriate rules for agricultural production aimed at supporting precision farming. Precision agriculture management practices can significantly reduce the amount of nutrients, pesticides, and other crop inputs [38-39]. Catchment management focused on the introduction of cost-effective ecological agricultural systems and was supported by various measures aimed at lake revitalization that would provide the opportunity to restore the good ecological status of lakes in a relatively short period of time. One of the tools for effective catchment management is a database of historical and contemporary information on rivers, lakes, and catchments. Such a database allows for the analysis of relationships between the different elements of the environment, control over the current situation in the lake basin and catchment area, evaluation of the effectiveness of actions taken to improve water quality, and planning future environmental projects.

\section{Acknowledgements}

This study was funded by the National Science Center, Poland (NCN), under project N N306 699940.

\section{References}

1. BURNEY J.A., DAVIS S.J., LOBELL D.B. Greenhouse gas mitigation by agricultural intensification. Proceedings of the National Academy of Sciences of the United States of America 107, 12052, 2010.

2. SHIKLOMANOV I.A. Appraisal and assessment of world water resources. Water Int. 25, 11, 2000.

3. HOEKSTRA A.Y., CHAPAGAIN A.K. Water footprints of nations: Water use by people as a function of their consumption pattern. Water Resources Management 21, 35, 2007.

4. PARRIS K. Impact of Agriculture on Water Pollution in OECD Countries: Recent Trends and Future Prospects, International Journal of Water Resources Development 27, 33, 2011.

5. O'BANNON C., CARR J., SEEKELL D.A., D'ODORICO P. Globalization of agricultural pollution due to international trade, Hydrol. Earth Syst. Sci. 18, 503, 2014.

6. LEWIS JR. W.M., WURTSBAUGH W.A. Control of lacustrine phytoplankton by nutrients: erosion of the phosphorus paradigm. Int. Rev. Hydrobiol. 93, 446, 2008.

7. CARPENTER S.R., BENNET E.M. Reconsideration of the planetary boundary for phosphorus. Environ. Res. Lett. 6, 1, 2011.

8. BAJKIEWICZ-GRABOWSKA E. The influence of the physical geographic environment on the biogenous matter delivery to the lake. J. Hydrol. Sci. 8, 63, 1981.

9. GÓRNIAK A. The role of hydrology and the nature of the basin in the formation of water chemistry of lakes. [in:] Modern research trends in hydrobiology. Conference materials, Supraśl, Białystok, 61, 1999 [In Polish].

10. VOLLENWEIDER R.A. Scientific fundamentals of the eutrophication of lakes and flowing waters, with particular reference to nitrogen and phosphorus as factors of eutrophication. Organisation for Economic Co-operation and Development, Paris, pp. 159, 1968.

11. ZDANOWSKI B. The purity of lakes and the possibility of their use for fish farming. [in:] Fish farming in lakes. Current state, conditions, outlook. The First National Conference of Users of Lakes, Uroczysko Waszeta, A. Wołos (ed.), Olsztyn, 7, 1996 [In Polish].

12. KAJAK Z. Eutrophication of lakes, PWN, Warszawa, pp. 232, 1979 [In Polish].

13. LOSSOW K. Reclamation of lakes and reservoirs achievements, opportunities and perspectives [in:] Protection and Restoration of Lakes and Reservoirs. Conference materials, Międzyzdroje, Sci. Inf. Office. Szczecin, 47, 1996 [In Polish].

14. KÖSE E., TOKATLI C., ÇIÇEK A. Monitoring Stream Water Quality: A Statistical Evaluation. Pol. J. Environ. Stud. 23, 1637, 2014.

15. SMITH V.H. Eutrophication of freshwater and coastal marine ecosystems: A global problem. Environmental Science and Pollution Research 10, 126, 2003.

16. JOHNES P.J. Understanding lake and catchment history as a tool for integrated lake management. Hydrobiologia 395, 41, 1999.

17. FERRIER R.C., JENKINS A. The Catchment Management Concept. [in:] Handbook of Catchment Management, R. C. Ferrier and A. Jenkins. (eds), Wiley-Blackwell, Oxford, 560, 2009.

18. SZALIŃSKA E., DOMINIK J. Water Quality Changes in the Upper Dunajec Watershed, Southern Poland. Polish J. Environ. Stud. 15, 327, 2006. 
19. HUS T., PULIKOWSKI K. Content of Nitrogen Compounds in Waters Flowing Out of Small Agricultural Catchments. Polish J. Environ. Stud. 20, 895, 2011.

20. MATYSIK M., ABSALON D., RUMAN M. Surface Water Quality in Relation to Land Cover in Agricultural Catchments (Liswarta River Basin Case Study). Pol. J. Environ. Stud. 24, 175, 2015.

21. PASZTALENIEC A., KUTYŁA S. The Ecological Status of Lakes in National and Landscape Parks: Does the Location of a Lake and Its Catchment within a Protected Area Matter? Pol. J. Environ. Stud. 24, 227, 2015.

22. KONDRACKI J. Regional Geography of Poland, Wyd. Nauk. PWN, Warszawa, 440, 2009 [In Polish]

23. GIBBARD P., VAN KOLFSCHOTEN T. The Pleistocene and Holocene Epochs [in:] A Geologic Time Scale, Gradstein F. M., Ogg J. G., and Smith A. G. (eds.), Cambridge University Press, 589, 2004.

24. HARASIMIUK M., MICHALCZYK Z., TURCZYŃSKI M. Łęczna-Włodawa Lakes, Maria Curie-Sklodowska University, Lublin, 208, 1998 [In Polish].

25. CHOIŃSKI A. Catalog of Polish Lakes, Wyd. Nauk. UAM, Poznań, pp. 600, 2007 [In Polish].

26. DE LA CRETAZ A.L., BARTEN P.K. Land Use Effects on Streamflow and Water Quality in the Northeastern United States. CRC Press, 344, 2007.

27. NEARY D.G., ICE G.G., JACKSON C.R. Linkages between forest soils and water quantity and quality. Forest Ecology and Management 258, 2269, 2009.

28. WEBB A.A., BONELL M., BREN L., LANE P.N.J., MCGUIRE D., NEARY D.G., NETTLES J., SCOTT D.F., STEDNICK J.D., WANG Y. Revisiting Experimental Catchment Studies in Forest Hydrology. Wallingford, Oxfordshire, UK, IAHS Publication, 240, 2012.

29. DAVIS M. Nitrogen leaching losses from forests in New Zealand. New Zealand J. For. Sci. 44, 2, 2014.
30. KREBS J. The Ecological World View. University of California Press, 592, 2008.

31. DUNN S.M., SAMPLE J., POTTS J., ABEL C., COOK Y., TAYLOR C., VINTEN A.J.A. Recent trends in water quality in an agricultural catchment in Eastern Scotland: elucidating the roles of hydrology and land use. Environ. Sci. Process. Impacts 16, 1659, 2014.

32. SOJKA M., MURAT-BŁAŻEJEWSKA S., KANCLERZ J. Assessment of non-point anthropogenic pressures on water quality of Struga Dormowska stream. Acta Sci. Pol. Form. Cir. 7 (2), 15, 2008 [In Polish].

33. SZYMCZYK S. Influence of the type of soil dewatering and land use on the dynamics of concentrations and volume of nitrogen discharged from agricultural areas. Journal of Elementology: 15, 189, 2010.

34. SCHINDLER D.W. A hypothesis to explain differences and similarities among lakes in the Experimental Lakes Area (ELA), northwestern Ontario. Journal of the Fisheries Research Board of Canada 28, 295, 1971.

35. STEFANIDIS K., PAPASTERGIADOU E. Relationships between lake morphometry, water quality and aquatic macrophytes in Greek lakes. Fresenius Environmental Bulletin 21, 3018, 2012.

36. LIU W., ZHANG Q., LIU G. Effects of Watershed Land Use and Lake Morphometry on the Trophic State of Chinese Lakes: Implications for Eutrophication Control. Clean - Soil, Air, Water 39, 35, 2011.

37. CORDER G.W., FOREMAN D.I. Nonparametric Statistics: A Step-by-Step Approach, Wiley, 288, 2014.

38. DIACONO M., RUBINO P., MONTEMURRO F. Precision nitrogen management of wheat. A review. Agron. Sustain. Dev. 33, 219, 2013.

39. DAVIS A.M., PRADOLIN J. Precision Herbicide Application Technologies To Decrease Herbicide Losses in Furrow Irrigation Outflows in a Northeastern Australian Cropping System. J. Agric. Food Chem. 64, 4021, 2016. 